\title{
Sujeito, Singularidade e Interpretação em Psicanálise*
}

JOEL BIRMAN**

\author{
Para Daniela, que constrói o seu estilo singular nos \\ caminhos incertos de sua curiosidade. \\ “...o que afirmássemos como sendo sua essência, não seria \\ sua verdade, mas somente o nosso saber sobre ela..." \\ (E.W.F. Hegel, A Fenomenologia do Espirito $)^{1}$
}

\section{O comentário como leitura de pressupostos}

Este texto pretende ser um comentário, pois tem a intenção de sublinhar os pressupostos da concepção psicanalítica de interpretação no ensaio de Piera

* Este texto é o desenvolvimento e uma nova versão do trabalho apresentado no VIII Fórum Internacional de Psicanálise, organizado pela Federação Internacional de Psicanálise, realizado no Rio de Janeiro, em outubro de 1989, como comentário ao texto "Le Je et ses interpretations", de P. Aulagnier, relatório oficial deste congresso.

** Professor do Instituto de Medicina Social da UERJ.

1 HEGEL E.W.F., La Phénoménologie de l'esprit (1807). Introduccion. Volume I, Paris, Aubier, 1941, p. 73. 
Aulagnier. Evidentemente a sua concepção não é a única, e a autora mesmo reconhece que existem posições teóricas diversas na psicanálise. Essa diversidade se funda em diferentes discursos metapsicológicos, na medida em que os psicanalistas privilegiam diferentes dimensões na metapsicologia freudiana. ${ }^{2}$ Assim, as diversas perspectivas existentes no campo teórico da psicanálise fundam-se em discursos metapsicológicos diferentes, que geram concepções também diferenciadas do que sejam o processo e a interpretação psicanalíticos. P. Aulagnier reconhece positivamente a relatividade de sua posição, que vamos destacar.

Qualquer comentário sobre o trabalho em foco supõe, antes de mais nada, reconhecer a mestria de $\mathrm{P}$. Aulagnier em psicanálise. Com efeito, diante de um ensaio original como o que foi apresentado, baseado em "trinta anos" de experiência psicanalítica, o mais importante é destacar a sua lógica conceitual. Esta razão desdobra-se numa outra: de forma intuitiva ou fundamentada em rigorosa leitura da teoria psicanalítica, qualquer psicanalista tem uma concepção do que seja a interpretação. E, em qualquer caso ela nunca é ingênua, pois traz consequiências éticas inevitáveis nos diferentes processos psicanalíticos que o analista promove.

O que se passa com a concepção de interpretação certamente é algo similar aquilo que Laplanche disse sobre a metapsicologia em psicanálise: que cada analista tem certamente a sua "metapsicologia de bolso"3 Talvez essa formulação se aplique com mais rigor à concepção de interpretação do que à metapsicologia, na medida em que a primeira é um instrumento básico no ofício de psicanalisar, apesar de a idéia de interpretação estar sempre fundada numa concepção metapsicológica. Separando "intuição" e "rigor", pode-se entrever aqui uma fronteira crucial entre dois estilos no discurso psicanalítico, cuja demarcação se dá pela existência ou não de uma fundamentação metapsicológica.

Por isso mesmo é fundamental destacar a lógica conceitual que norteia as intuições e as concepções sobre 0 ato de interpretação, pois circunscrevendo $o$ campo teórico das diferenças pode-se elaborar as condições para a existência de um diálogo fecundo entre analistas sobre a experiência analítica. Essa exigência se impõe principalmente quando se vai examinar um texto meti-

2 AULAGNIER P., Le Je et ses interprétations. Paris, 1989, mimeografado, p. 5.

3 Sobre isso, ver: LAPLANCHE J., "A pulsão e seu objeto-fonte: seu destino na transferência”, in LAPLANCHE J., Teoria da sedução generalizada e outros ensaios. Porto Alegre, Artes Médicas, 1988; LAPLANCHE J., "Traumatismo, tradução, transferência e outros transes". Idem. 
culoso, como o que nos é apresentado, que pretende fundar com rigor a concepção psicanalítica de interpretação.

Diálogo fundamental, sem dúvida, porque se a psicanálise não é uma "ciência exata", ela não é certamente uma "mística", como pontua P. Aulagnier com pertinência. ${ }^{4}$ Entretanto, não deixa de ser surpreendente a facilidade com que as instituições analíticas se negam a qualquer diálogo. Certamente, os destinos da transferência nas instituições analíticas nos permitem interpretar o sentido assumido por essas cristalizações institucionais e seus efeitos sobre a posição subjetiva dos psicanalistas. O que é espantoso nessas circunstâncias é que a psicanálise pretenda ser a condição de possibilidade para que o sujeito possa assumir a verdade de sua história e do seu desejo, o que dificilmente poderá realizar-se nos contextos onde o discurso psicanalítico adquire uma conotação de ordem "mística". Por isso mesmo, é preciso destacar as bases de nossos discursos teóricos, para que um diálogo efetivo possa se empreender, de forma a não ficarmos ilhados numa Babel psicanalítica.

O comentário que se segue destaca quatro tópicos que organizaram a minha leitura. ${ }^{5}$ Inicialmente, vou enfatizar o conceito de sujeito que perpassa este escrito. Em seguida, vou sublinhar como essa concepção epistemológica se articula numa certa perspectiva metapsicológica. Nesse contexto, se insere uma definição do que seja a demanda em psicanálise. Finalmente, vou delinear a concepção de interpretação que P. Aulagnier nos propõe.

\section{O sujeito em questão}

A formulação básica que norteia o ensaio é a seguinte: a problemática da interpretação se impõe em psicanálise porque, antes de mais nada, o sujeito que é o suporte da experiência psicanalítica já é interpretação. Não existe qualquer relação de exterioridade entre esses dois termos. O que implica considerar que o sujeito em psicanálise é supostamente um intérprete, que tem como referência a relação com o Outro e o discurso do Outro.

4 AULAGNIER P., Le Je et ses interprétations. Op. cit., p. 18.

5 Como a realização do comentário de um tex to implica sempre um trabalho de interpretação, me apoiarei nas obras mais importantes da autora para não ser arbitrário. Sobre isso, ver: AULAGNIER P., La violence de l'interprétation. Paris, Presses Universitaires de France, 1975; AULAGNIER P., Les destins du plaisir. Paris, Presses Universitaries de France, 1979; AULAGNIER P., L'apprenti-historien et le maître sorcier. Paris, Presses Universitaires de France, 1984 
Evidentemente, a concepção de sujeito tal como formulo acima não se encontra literalmente enunciada nesse texto, pois o que se enuncia é o conceito do $J e$. Parece-nos que o conceito de sujeito é adequado para se referir ao Je e para as suas prefigurações destacadas por P. Aulagnier na genealogia do psiquismo, pois esta evidentemente discrimina, a partir de Lacan, os conceitos de $J e$ e de Moi. Nessa perspectiva, podemọ afirmar que mesmo que a instância do $J e$ em P. Aulagnier não se superponha ao conceito de $J e$ em Lacan, existe uma evidente referência à problemática do sujeito.

A problemática da interpretação não se restringe, assim, a uma questão de ordem técnica, como sustenta uma longa e controvertida tradição psicanalítica, pois esta problemática só se impõe na medida em que o sujeito já é interpretação. Desta forma, a autora define os pressupostos do sujeito, dos quais deriva a sua leitura sobre o processo e a interpretação psicanalíticos.

De fato, só pode existir a interpretação como modalidade de intervenção analítica na medida em que, de direito, o sujeito em psicanálise tem o estatuto de produtor de interpretações sobre o seu presente, num contraponto permanente ao seu passado e ao seu futuro. Nesse contexto, centrado na interpretação, o passado pode ser constantemente reestruturado mediante uma interpretação forjada no presente, e o futuro pode ser projetado como horizonte de possibilidades entreaberto pela interpretação. Por isso mesmo, P. Aulagnier pôde formular que a interpretação não se refere a uma mítica experiência originária, considerando esta como um referencial absoluto e um signo a ser revelado pela primeira vez na história do sujeito. A interpretação incide sobre uma interpretação já articulada pelo Je na sua história e nos feitos cruciais que esta interpretação tem sobre o psiquismo. ${ }^{6}$

A problemática do sujeito como interpretação se articula a uma outra formulação que opera como o seu desdobramento imediato; a de que o tema do sujeito em psicanálise é de ordem estritamente intersubjetiva. Vale dizer, a idéia de sujeito implica necessariamente um outro sujeito como contraponto fundamental para a sua constituição e reconstituição permanente. Este só se constitui a partir de um outro que, como intérprete e possibilitador de objetos de satisfação, fornece as condições de possibilidade para a sua estruturação. P. Aulagnier pôde então afirmar que a interpretação do sujeito é inseparável das interpretações que o outro sujeito realiza sobre os efeitos psíquicos do encontro de ambos. ${ }^{7}$ Nessa perspectiva, destaca-se no ensaio um conjunto de termos que alude diretamente ao estatuto intersubjetivo do sujeito. Podemos

6 Aulagnier P., Le Je et ses interprétations. Op. cit., pp. 4-5.

7 Idem, p. 14. 
sublinhar alguns: "história relacional", 8 "experiência relacional"9 e "espaço relacional”. ${ }^{10}$ P. Aulagnier é bastante enfática ao afirmar a dimensão intersubjetiva que caracteriza o sujeito, para afastar qualquer dúvida sobre a importância crucial que confere a esse registro no seu discurso. ${ }^{11}$

É preciso sublinhar como a dimensão intersubjetiva ocupa um lugar central nessa concepção de sujeito, mediante a utilização de certos conceitos. Assim, a história do psiquismo é representada em torno de encontros fundamentais que, como parâmetros intersubjetivos, ordenam a construção do psíquico: encontro entre o psiquismo do infante e o espaço fora do psíquico, encontro entre o psiquismo e o discurso materno, encontro entre o $\mathrm{Je}$ e o tempo. ${ }^{12}$ Esses encontros definem sempre um espaço entre sujeitos, pois a única realidade a que se remete o sujeito é a "realidade humana". ${ }^{13}$ De forma ainda mais fundamental, P. Aulagnier enuncia que a instância do $J e$ é fundada no registro inter-relacional, de forma que é impossível para o $\mathrm{Je}$ se representar fora desse registro, do campo do investimento, pois essa exclusão implicaria a sua morte. ${ }^{14}$ Nessa perspectiva, são bastante elucidativos desse atributo intersubjetivo os comentários sobre as condições de possibilidade para a estruturação da instância do $J e$ na história do psiquismo, desde o reconhecimento da especificidade do infante e da sua alteridade no momento do nascimento até os momentos posteriores de sua estruturação. Este tópico, contudo, introduz o discurso metapsicológico, que retomaremos adiante.

Fundado na interpretação e no registro intersubjetivo, o sujeito se insere também na ordem do tempo, definindo, então, a sua terceira dimensão constitutiva como sendo da ordem da história. É essa abertura possibilitada pela interpretação que, ao conferir mobilidade ao sujeito, lhe permite simultaneamente construir uma história, de forma a retificar interpretações passadas e anunciar novas modalidades de relações no futuro. É nesse contexto que se insere

8 Idem, p. 1.

9 Idem, p. 4.

10 Idem, p. 5.

11 “... Cette lecture du conflit explique l'importance que j'accorde aux effets d'inter-réaction réciproques et il faut souligner le terme réciproque, à l'oeuvre du premier au dernier jour de notre existence dans notre vie relationnelle et, de ce fait, dans notre vie tout court". Idem, p. 9. O grifo é nosso.

12 Idem, pp. 10-16.

13 Idem, p. 8.

14 Idem, pp. 7-8. 
a problemática da memória: fundada nos registros da interpretação e da intersubjetividade, a memória também é marcada inevitavelmente pela ordem do tempo.

O registro do sujeito que inscreve a interpretação na temporalidade é o que permite a crítica mais contundente a qualquer determinismo no campo da psicanálise: a história do sujeito é aberta para a transformação, pois é inevitavelmente marcada por um processo de reinterpretação sucessiva. A existência do sujeito é, então, marcada pela imprevisibilidade. ${ }^{15}$

Além desses atributos destaca-se uma quarta dimensão, sem dúvida de importância crucial. O sujeito é marcado pela singularidade. O saber e a ética psicanalíticos decorrem dessa dimensão singular, que constitui a especificidade da psicanálise. É o reconhecimento dessa marca singular que deve nortear a escuta do analista nos diferentes momentos da experiência analítica.

Sobre a singularidade, P. Aulagnier fornece indicações importantes para pensarmos não apenas as condições para a constituição do sujeito como também as exigências éticas que regulam a experiência psicanalítica. É nesse contexto que se delineia um campo complexo de indagações sobre os limites suportáveis da dor psíquica e sobre os efeitos mortíferos das expectativas de um outro no psiquismo de um sujeito.É aqui também que se tece a articulação entre a palavra verídica do analista e o afeto do analisante, pois se existe uma relação essencial entre a interpretação e a possibilidade de promover a reabertura de uma história, é fundamental para isso a experiência afetiva do analisante. A singularidade do sujeito representa a tessitura dessas diferentes exigências.

Finalmente, destacamos um quinto atributo do sujeito, para caracterizar a importância crucial do investimento libidinal na sua constituição e reconstituição em psicanálise. Inserida nos registros da interpretação, da intersubjetividade e da história, a singularidade do sujeito é marcada pelo investimento. Com isso, retira-se qualquer conotação intelectualista da representação do sujeito. Portanto, no campo psíquico definido pelas potencialidades do investimento e do desinvestimento, o sujeito pode tanto se manter em movimento, como intérprete de sua história, quanto se imobilizar num sistema interpretativo fechado e ficar, então, impossibilitado de existir. Porém, se este último atributo do sujeito não indica, como exigência teórica, qualquer novidade na tradição freudiana, em contrapartida a inovação se coloca nos termos como se tematiza essa exigência. É nesse contexto que se impõe a problemática do afeto e da

15 Idem, pp. 6-7. 
emoção em psicanálise, apesar de P. Aulagnier salientar o quanto é discutível essa questão no discurso freudiano. ${ }^{16}$

Entretanto, se o investimento do sujeito é a condição sine qua non para a sua sobrevivência, a modalidade do investimento se articula com os atributos anteriormente destacados. A articulação entre essas várias dimensões do sujeito indica a consistência do discurso teórico de P. Aulagnier. Com efeito, se o sujeito como interpretação supõe o investimento libidinal para que possa se manter em movimento como intérprete de sua história, o investimento supõe o agenciamento do outro nesse percurso, tanto como suporte e possibilitador de objetos pulsionais de satisfação quanto como intérprete da experiência do sujeito. Além disso, o investimento do sujeito e o limite da dor psíquica delineiam as condições nas quais a singularidade se impõe, para que o sujeito possa não apenas existir como também ser reconhecido por um outro.

\section{Uma metapsicologia do sujeito}

A metapsicologia é o discurso teórico que pretende esboçar uma cartografia segura para orientar o analista na experiência psicanalítica. Por isso mesmo, o discurso metapsicológico revela a representação do ato psicanalítico que é assumido pelo analista, fundando as exigências que sustentam a sua escuta e norteiam as suas intervenções. A leitura da metapsicologia de um autor permite, portanto, apreender as suas preocupações centrais como psicanalista.

Inicialmente, pretendemos sublinhar o cuidado e a delicadeza, face aos possíveis efeitos do sofrimento psíquico, que se destacam na postura de $\mathrm{P}$. Aulagnier. Essas dimensões assumem grande relevo, pois articulam a construção da história mítica do sujeito e a direção que norteia a escuta do analista. Esta postura de cuidado e delicadeza, que deveria caracterizar a figura materna no trato originário com o infante e marcar a posição do analista, remete a duas grandes oposições: expectativa/decepção e investimento/desinvestimento. Estas oposições poderiam dar conta, como operadores conceituais, da ordenação do espaço originário do infante e de suas reestruturações posteriores, de onde miticamente vai se constituir o sujeito, a partir dos três encontros fundamentais a que o psiquismo vai ser inevitavelmente exposto: encontro entre o psiquismo do infante e o espaço fora do psiquismo, encontro entre o psiquismo e o discurso materno, e o encontro entre o $J e$ e o tempo. ${ }^{17}$

16 Idem, p. 15.

17 Idem, pp. 10-16 
Esses encontros estruturais remetem para as três provas cruciais a que é submetido o psiquismo ao longo de sua história: a frustração, a separação e a castraçãoo ${ }^{18}$ Nessa perspectiva, destacam-se a retomada do conceito de trau$m a^{19}$ e a relevância conferida a "meio psíquico ambiente". ${ }^{20} \mathrm{O}$ trauma, porém, é delineado no contexto definido pela relação intersubjetiva e pela interpretação, não sendo pois um conceito meramente econômico, e o "meio psíquico ambiente" é também enfocado num contexto essencialmente intersubjetivo. O pressuposto aqui presente é de que esses encontros representam provas cruciais para o psiquismo, na medida em que são passíveis de provocar conflito e dor psíquicos, pois a experiência da satisfação plena da pulsão é da ordem do impossível. Daí porque, em diferentes níveis da estrutura psíquica, tanto na frustração como na separação e na castração, se indica essa impossibilidade da plenitude do gozo. Nesse contexto é que se impõem a retomada do conceito de trauma e a importância do outro na constituiçẫo do psiquismo.

Com efeito, o trauma não remete a um acontecimento fortuito na história do sujeito mas se apresenta como uma dimensão constitutiva do psiquismo, na medida em que são os seus efeitos múltiplos que impõem ao sujeito um trabalho permanente de interpretação do seu sentido intersubjetivo. Assim, quanto maior for o investimento num objeto de desejo, maior será também, em contrapartida, o efeito conflitivo e até mesmo traumático produzido pela impossibilidade da satisfação. ${ }^{21}$ Assim, o conflito psíquico se impõe como constitutivo do futuro sujeito, com os possíveis efeitos de intrincação e de desintrincação das pulsões, e entre libido narcísica e libido de objeto. ${ }^{22}$ Então, o conceito de pulsão de morte pode se enunciar, de maneira rigorosa, como sendo o "desejo de não desejar", para que o psiquismo não se exponha dramaticamente ao conflito $\mathrm{e}$ ao sofrimento psíquicos provocados pela impossibilidade de satisfação plena da pulsão. ${ }^{23}$

Os processos originário, primário e secundário correspondem aos encontros fundamentais na constituição do psiquismo e às provas cruciais a que este é exposto na sua estruturação. Porém, a seqüência desses processos não se regula por uma 1ógica genético-evolutiva, pois os processos posteriores não abolem os anteriores, que permanecem em funcionamento na estrutura psí-

\footnotetext{
18 Idem, p. 6.

19 Idem, pp. 6-7.

20 Idem, p. 6.

21 Idem, p. 9.

22 Iden, pp. 8-9.

23 Idem, p. 9.
} 
quica. $^{24}$ Se o processo pictográfico remete para o pictograma como o seu correlato na ordem da representação, o processo primário se relaciona com o fantasma e o processo secundário remete para a ordem do enunciado, onde se inscreve o Je.

Destaquemos a dinâmica intersubjetiva, essencial para a instalação psíquica do infante. Assim, se na constituição originária do psiquismo não existe ainda alteridade constituída no infante, é preciso que a figura materna possibilite ao infante as condições de satisfação pulsional, de tal maneira que aquele acredite que pode produzir os seus objetos de satisfação e não está condenado a se expor à experiência mortífera da dor psíquica. É aqui que se destaca não apenas a importância da antecipação materna frente às possíveis demandas do infante, mas também como a figura materna funciona como interprete e possibilitadora de objetos de satisfação para ele. Então, a futura alteridade entre o sujeito e o outro é prefigurada na relação fundamental entre a zona erógena e o objeto de satisfação, relação esta que constitui o esquema dinâmico que é o pictograma. A mediação feita por esse esquema pode introduzir duas figurações polares, que delineiam destinos psíquicos diferenciados: 'boa' boca/seio-prazer e 'má' boca/seio-sofrimento. Nessas figurações trata-se para o infante de uma situação de auto-engendramento, e o que se transforma é o verbo da enunciação em pauta. Isto é, no primeiro caso a 'boa' boca produz o seio-prazer, e no segundo a 'má' boca destrói o seio-sofrimento. ${ }^{25}$

É importante salientar como essa leitura metapsicológica se funda na epistemologia do sujeito, anteriormente traçada. Assim, se inicialmente não existe alteridade no infante, a figura materna o introduz no universo intersubjetivo, mediante a antecipação e a prefiguração da intersubjetividade. Para isso é preciso que a mãe possa, como intérprete do infante, ser sensível às suas demandas, de forma a oferecer os objetos de satisfação que possam impedir os efeitos mortíferos do sofrimento psíquico. Para realizar essa função, é fundamental que a figura materna domine no seu psiquismo a possível decepção que $o$ infante pode provocar nas suas expectativas. Portanto, a possibilidade de a figura materna ser sensível às demandas do infante tem como contrapartida o seu poder de suportar as possíveis decepções que o infante lhe provoca. ${ }^{26}$

Temos, portanto, a correlação entre duas oposições fundamentais, que remetem para 0 equilíbrio/desequilíbrio no contexto prefigurado da relação intersubjetiva, delineando, por um lado, a oposição investimento/desinves-

24 Idem, p. 12.

25 Idem, pp. 10-13.

26 Idem, pp. 10-12. 
timento e, por outro, a oposição libido narcísica/libido de objeto. Essas oposições funcionam em ambos os pólos da relação em pauta, compreendendo que a figura materna funcione inevitavelmente como responsável pela introdução do infante no universo intersubjetivo. Essas mesmas oposições se inserem na experiência psicanalítica, na qual o conflito entre expectativa e decepção se coloca para o analista e para o analisante. ${ }^{27}$ Enfim, é a possibilidade da figura materna dominar suas decepções de ordem narcísica que lhe permite manter a abertura desejada para o infante. Desse fator depende, pois, a possibilidade de reconhecimento da singularidade do infante como sujeito.

Nesse contexto, a figura materna realiza a função primordial de paraexcitação, enunciada por Freud em Além do princípio do prazer, e retomada por P. Aulagnier como função de para-desinvestimento. Com a constituição posterior da instância do $J e$, essa função será inserida pelo sujeito na sua atividade interpretante, para impedir a "evaporação" (Orwell) de uma experiência relacional. ${ }^{28}$

Portanto, a instância do $\mathrm{Je}$, como intérprete da experiência intersubjetiva, é a resultante de um processo iniciado no registro do pictograma, no qual o sujeito mantém em aberto a possibilidade de transformar o sentido de suas experiências pretéritas e de remanejar o seu campo de investimentos. Nessa concepção metapsicológica, os diferentes atributos do sujeito se imbricam nos registros do originário, do primário e do secundário. Entretanto, o que se destaca nessa concepção é o reconhecimento da singularidade, pois o sujeito singular é a resultante da diferença entre expectativa e decepção no contexto intersubjetivo.

\section{A demanda e a experiência psicanalítica}

Esses comentários tornam possível delinear o sentido da experiência psicanalítica, começando por aquilo que possibilita a demanda de análise. No início do ensaio, P. Aulagnier indica o que é comum na neurose e na psicose: a inexistência de uma certa mobilidade e de uma interrogação básicas que poderiam operar sobre as versões forjadas pelos sujeitos para suas histórias infantis. Assim, se na neurose esse impasse se apresenta como 'recusa' e na psicose como 'impossibilidade', ambas produzem um ponto morto, impedidos que estão os sujeitos de questionar a interpretação que formularam sobre a neurose infantil. ${ }^{29}$ Essa imobilidade é fonte de sofrimento e indica um evidente

27 Idem, pp. 1-5.

28 Idem, pp. 12-13.

29 Idem, p. 1. 
impasse para o sujeito. O reconhecimento desse impasse é a condição de possibilidade do processo analítico, cuja finalidade será produzir um movimento interpretativo. Entre a estagnação e a mobilidade interpretativa do sujeito, a psicanálise pretende reabrir um sistema interpretativo. Isso não significa, porém, que o sujeito, frente a um impasse dessa ordem, demande necessariamente uma análise. A passagem de uma condição necessária para a suficiente é definida pela impossibilidade existencial em que o impasse se configura para o sujeito.

Pretendo enfatizar que a impossibilidade de colocar em movimento a interpretação é que produz a estagnação no sujeito. Nesse contexto, a história se congela num impasse, pois a interpretação forjada no tempo passado não permitiu qualquer reabertura para o presente e o futuro. Assim, a psicanálise é uma possibilidade que se oferece ao sujeito para a reabertura do seu sistema interpretativo, de maneira a permitir o exame de seus conflitos, que conduziram à estagnação atual. Enfim, um novo contexto inter-relacional é oferecido ao sujeito para reabrir o seu tempo passado e promover um processo de reinterpretação.

Então, na demanda de análise existe a busca de reversão de um sistema interpretativo, mediante um processo de reinterpretação que promova a reabertura do presente face a um possível futuro. Porém, esse apelo é feito para um outro que, como interrprete, pode relançar a totalidade do processo e possibilitar a reabertura do impasse. Evidentemente, este impasse traz a marca da singularidade do sujeito a quem cabe, pela reabertura do processo interpretativo, oferecer um outro destino. Finalmente, o investimento libidinal se revela não apenas pela demanda do analisante, como também na acolhida do analista, ao se engajar no processo analítico. O que implica dizer que ao analistaé designado um duplo lugar na experiência psicanalítica - o de um sujeito suposto saber e o de um sujeito suposto desejo - , tanto pela reabertura de sentido que pode sustentar quanto pelo investimento necessário para que o processo analítico possa existir.

\section{Ato interpretativo, surpresa e singularidade}

Esses pressupostos é que permitem formular de forma rigorosa a questão da interpretação em psicanálise. ${ }^{30}$ Vejamos a relação que a noção de singularidade mantém com a concepção designada como interpretação surpresa.

30 Idem, pp. 16-22. 
O conceito de interpretação como surpresa é o contraponto da figura da interpretação como sistema, isto é, como sistema de interpretação. Este representa justo o oposto do que se pretende numa análise, isto é, relançar o analisante numa mobilidade interpretativa que lhe permita deslocar-se do seu sistema de interpretação estagnante. Portanto, na experiência psicanalítica não se pretende que $o$ analisante substitua o seu sistema de interpretação pelo do analista, mas que o sujeito possa retomar a mobilidade interpretativa necessária para delinear a singularidade de sua história e do seu desejo. O atributo surpresa que caracteriza a interpretação articula-se à idéia de sujeito singular, que se opõe decisivamente ao sistema de interpretação como uma referência abstrata e codificada a priori.

Nesse contexto, o conceito de interpretação em psicanálise, em sentido estrito, se insere $n a$ experiência psicanalítica. Portanto, a interpretação em psicanálise é impensável fora do processo analítico. Com isso, a interpretação psicanalítica não se identifica com certas concepções filosóficas sobre a interpretação, como a da hermenêutica de Ricoeur. ${ }^{31}$ O que não implica dizer que a concepção psicanalítica de interpretação não possa oferecer subsídios importantes para uma reflexão filosరfica sobre a interpretação, desde que reconhecidas as condições de sua especificidade na experiência analítica. Portanto, a concepção de interpretação em psicanálise é inseparável do projeto psicanalítico. Enfim, a interpretação não é sistema interpretativo, na medida em que não é um código fechado de significações, estabelecido a priori, mas um instrumento específico de intervenção do analista, que se insere na lógica da experiência analítica.

Entretanto, independentemente da concepção hermenêutica, a idéia de interpretação como sistema tem, em psicanálise, uma incidência marcante que é importante destacar. Supomos que é por isso que P. Aulagnier retoma essa questão diversas vezes. Apesar de o sistema interpretativo como concepção ter uma origem pré-freudiana, apresenta-se na história da psicanálise repetidas vezes. No momento, não cabe indicar algumas dessas formulações, mas registrar a sua 'ineficácia' e reiterar o seu caráter essencialmente antipsicanalítico. ${ }^{32}$

31 Sobre isso, ver: RICOEUR P., De l'interprétation. Essais sur Freud. Paris, Seuil, 1965; RICOEUR P., Le conflit des interprétations. Essais d'herméneutique. Paris, Seuil, 1969, pp. 101-207.

32 Sobre isso, ver: AULAGNIER P., "Un problème actuel: les constructions psychanalytiques," in Topique, número 3. Paris, Presses Universitaires de France, 1970, pp. 61-96. 
Com efeito, nessa concepção de sistema interpretativo ocorre um esquecimento fundamental: na experiência analítica se encontram duas figuras singulares, e essa singularidade do sujeito é o que cabe ser restaurado na análise ou ser enunciado pela primeira vez. Por isso mesmo, o estatuto conceitual da neurose infantil, apesar de universalizante como qualquer conceito, apresentase de forma particular no percurso histórico de diferentes sujeitos. A neurose infantil do analista é do mesmo modo marcada pela singularidade, encontra-se encarnada na sua historia e na sua escuta. ${ }^{33}$ Se não existe uma neurose infantil abstrata, não pode existir, portanto, um sistema de interpretação marcado pela universalização do sentido. Enfim, é no contexto intersubjetivo da análise que as marcas da singularidade do sujeito assumem densidade, na medida em que o tempo passado, pertencente à sua história relacional, pode ser redimensionado pelo tempo presente de um outro campo relacional.

Por isso mesmo destaca-se um segundo atributo da interpretação em psicanálise. A interpretação se diferencia de outras modalidades de intervenção do analista na experiência psicanalítica. O que implica dizer que nem todos os atos de linguagem do analista são da ordem da interpretação. Da mesma forma como a interpretação não pode ser representada fora do projeto analítico, ela agora é enunciada como uma espécie de um gênero que podemos designar como intervenção do analista. Afirma-se, pois, que a logica da experiência analítica define o lugar, a função e o sentido da interpretação.

O psicanalista, portanto, realiza múltiplas intervenções no curso da análise, visando a produzir, no analisante, uma mobilidade interpretativa que se estagnou na versão forjada sobre sua neurose infantil. É preciso, então, manter a mobilidade do projeto analítico, promovendo a desarticulação do sistema interpretativo do analisante. No entanto, se isso possibilita a retomada do seu investimento libidinal como sujeito da interpretação, no sentido abrangente que destacamos no início, permitindo a desconstrução da versão de sua história infantil, isso não constitui ainda a interpretação analítica no sentido estrito, mas é indubitavelmente a sua condição de possibilidade.

Nessa perspectiva, que é a interpretação psicanalítica? Antes de mais nada, um enunciado do analista. O que implica dizer que a palavra do analisante não é da ordem da interpretação, apesar de retomar, pela fala, a mobilidade interpretativa deste. A interpretação é, pois, um instrumento do analista, que é o seu agente. Além disso, a interpretação é da ordem do ato: ato de interpretar. Ato e palavra do analista. Então, a interpretação não é da ordem da compreen-

33 AULAGNIER P., Le Je et ses interprétations. Op. cit., pp. 19-20. 
são. Daí porque a interpretação analítica não é da ordem da hermenêutica, pois não se trata de revelar, pela palavra oracular do analista, um sentido oculto. No entanto, se a interpretação é da ordem da palavra e do ato, este ato implica uma responsabilidade do analista, e isto lhe confere uma dimensão ética.

Então, a questão se impõe: de que ética se fala aqui? De uma ética do desejo, evidentemente, pois P. Aulagnier destaca como o ato de interpretação supõe que o analista realize uma "ruptura momentânea" com a sua posição anterior de "observador" e de "experimentador" de uma experiência relacional, posição na qual o analista registra os lugares em que o analisante o situa como destinatário de suas demandas e se insere nessa experiência relacional. Essa ruptura implica o ato de reconhecimento, pelo analista, de um desejo até então indizível do analisante e o direito a este reconhecimento. Com ele o analisante se situaria numa posição desejante, excluída até então de suas possibilidades relacionais. Nesse contexto, a interpretação é uma experiência compartilhada entre analista e analisante, e se formula sempre num momento de grande investimento transferencial. Por isso mesmo, é um catalisador fundamental, que permite redirecionar decisivamente a palavra e a memória do analisante.

A surpresa, como característica fundamental da interpretação analítica, se justifica pelo inesperado do reconhecimento do desejo, que até então nunca fora enunciado para o analisante. Pela mediação desse reconhecimento, realizado no tempo presente da relação analítica, o tempo passado da história do analisante pode ser reordenado de maneira fulgurante.

No entanto, é no reconhecimento do desejo e no direito ao reconhecimento do desejo do analisante, realizado pelo analista, que se marca a intenção da singularidade e sua dimensão ética. Contudo, esta singularidade se coloca tanto para o analisante quanto para o analista. Para o primeiro, pois com esse reconhecimento ele pode identificar uma dimensão fundamental do seu ser, reinterpretando um fragmento do seu passado e forjando uma nova versão de sua história. Para o analista também, já que se a interpretação é ato e palavra, existe uma singularidade na escuta do desejo e na decisão de enunciar o seu reconhecimento, de maneira a engajar o analista em seu próprio nome, e não em defesa de qualquer sistema impessoal de interpretação. Por isso mesmo, produz-se o paradoxo de que, com o exercício da interpretação, a figura do analista vai se destituindo progressivamente do lugar de analista. 


\section{RESUMO}

\section{Sujeito, Singularidade e Interpretação em Psicanálise}

Este texto comenta um escrito inédito de P. Aulagnier, apresentado no VIII Fórum Internacional de Psicanálise, realizado no Rio de Janeiro em 1989. Baseando-se nas obras fundamentais de P. Aulagnier, o comentário destaca os pressupostos epistemológicos que fundam a concepção de sujeito no discurso teórico da autora (interpretação, intersubjetividade, temporalidade, singularidade e investimento libidinal). Desses pressupostos derivam os critérios que norteiam a sua leitura metapsicologica do psiquismo. Após tematizar a questão da demanda de análise, 0 autor destaca a idéia de que o conceito de interpretação psicanalítica não integra a leitura hermenêutica, sublinhando a ética do desejo inerente ao ato de psicanalisar.

\section{ABSTRACT}

\section{Subject, Singularity, and Interpretation in Psychoanalysis}

The article comments on an unpublished paper by P. Aulagnier, presented at the 8th International Forum on Psychoanalysis, held in Rio in 1989. Based on Aulagnier's foundational works, the present texthighlights the epistemological presuppositions that underpin the concept of subject in her theoretical discourse (interpretation, intersubjectivity, temporality, singularity, and libidinal investment) and from which the criteria that guide Aulagnier's metapsychological reading of the psyche are derived. After framing the question of demand for psychoanalysis, the article focuses on the idea that the concept of psychoanalytical interpretation is not part of a hermeneutic reading. It further stresses the ethics of desire inherent to the act of psychoanalyzing.

\section{RESUME}

\section{Sujet, Singularité et Interprétation en Psychanalyse}

Ce texte commente un texte inédit de P. Aulagnier presenté lors du VIIIè. Forum International de Psychanalyse réalisé à Rio de Janeiro en 1989. Il se base sur les oeuvres fondamentales de P. Aulagnier pour mettre en relief les prémisses épistémologiques qui fondent la conception de sujet dans le discours 
théorique de cet auteur (interprétation, intersubjectivité, temporalité, singularité et investissement libidinal). De ces prémisses dérivent les critères qui orientent sa lecture mètapsychologique du psychisme. Aprés avoir thématisé la question de la demande d'analyse, le commentateur souligne l'idée selon laquelle le concept d'interprétation psychanalytique n'appartient pas à la lecture herméneutique et met en évidence l'éthique du désir qui est inhérente à l'acte de psychanalyser. 